\title{
Utility of wound cultures in the management of open globe injuries: a 5- year retrospective review
}

\author{
Ryan T. Drumright ${ }^{1}$, Kathleen A. Regan², Albert L. Lin ${ }^{3}$, Meghan G. Moroux ${ }^{4}$ and Siva S. R. lyer ${ }^{5^{*}}$ (D)
}

\begin{abstract}
Background: Endophthalmitis after open globe injury can be devastating to vision recovery. As treatment of endophthalmitis is often empiric, some surgeons may obtain cultures at presentation of trauma in anticipation of later infection. This study examines the usefulness of wound cultures obtained during globe repair.

Results: Institutional Review Board approval was obtained. Medical records were retrospectively reviewed, with 168 open globes included. Cultures of the wound site had been taken in all cases included in this study. Wound cultures were positive in $63 \%$ of cases but were not used for clinical decision-making for any patient in this study. Two patients had evidence of endophthalmitis at presentation, with results of vitreous culture matching those from the wound. No patient later developed endophthalmitis after open globe repair.

Conclusions: Despite a high rate of wound contamination, few cases of endophthalmitis (1.2\%) were seen in this series. In no case did the results of wound culture impact choice of antibiotic prophylaxis or treatment. Cultures obtained at the time of open globe repair were not cost effective in the subsequent management of the injury.
\end{abstract}

Keywords: Globe trauma, Endophthalmitis, Culture, Open globe injury

\section{Background}

Open globe injury results from penetration or perforation in sharp or projectile trauma or from rupture in blunt trauma [1]. Endophthalmitis is a potentially devastating sequela of open globe injury. Rates of endophthalmitis after severe ocular trauma range from 0 to $17 \%[2,3]$, with a higher risk in the presence of an intraocular foreign body (IOFB) $[4,5]$. Outcomes are typically worse than post-operative endophthalmitis [2].

Prophylactic antibiotics may be administered, but data supporting a particular treatment protocol are scarce [6]. If endophthalmitis develops, treatment is often initiated empirically [7]. Staphylococcus and Streptococcus species are common causative agents [7], as they are skin flora and may enter through an open wound [2]. Some surgeons may obtain samples for culture at the time of globe repair to have a responsible microbial agent identified by the time the clinical picture worsens $[8,9]$. However, despite positive

\footnotetext{
* Correspondence: ssr@ufl.edu

${ }^{5}$ Department of Ophthalmology, University of Florida College of Medicine, 1600 SW Archer Rd, Gainesville, FL 32610, USA

Full list of author information is available at the end of the article
}

cultures even from intraocular sources at the time of open globe repair, endophthalmitis may not develop $[8,10]$.

Some surgeons, including those at our institution, routinely obtain wound cultures at the time of surgical repair $[7,8]$. The purpose of this study was to analyze the clinical usefulness and cost-effectiveness of this test in the care of open globe injury.

\section{Methods}

Institutional review board (IRB) approval was obtained at the University of Mississippi. This study was a retrospective non-comparative case series patient record review from June 2012 to April 2016. Electronic medical records were searched for a diagnosis code of open globe or corneal-scleral laceration and reviewed for correct coding. Patients who underwent primary globe repair, had wound cultures taken preoperatively, and followed up for at least 1 month post-operatively were included. Patients were excluded if the eye was primarily removed rather than repaired, if cultures were not obtained, or if they were lost to follow-up prior to 1 month. 
Table 1 Culture media used and cost of supplies

\begin{tabular}{ll}
\hline Culture media & $\begin{array}{l}\text { Cost (direct } \\
\text { from supplier) }\end{array}$ \\
\hline Blood agar & $\$ 4.40$ \\
Chocolate agar & $\$ 4.00$ \\
MacConkey agar & $\$ 3.07$ \\
Sabouraud Dextrose agar slant & $\$ 2.81$ \\
Sabouraud Dextrose with Chloramphenicol agar slant & $\$ 2.14$ \\
Mycosel agar slant & $\$ 1.47$ \\
Lowenstein-Jensen agar slant & $\$ 7.50$ \\
Thioglycollate broth with hemin and Vitamin K & $\$ 0.88$ \\
\hline
\end{tabular}

After induction of general anesthesia and endotracheal intubation, cultures were obtained from the wound site using cotton tip applicators. See Table 1 for listing of cultures obtained as a departmental standard in every case. The globe was then prepped with 5\% ophthalmic betadine and draped for ophthalmic surgery. Globe repair was performed by multiple faculty at a single institution with a variety of approaches corresponding to the nature of the injury. Ocular and systemic antibiotics were administered at the discretion of the surgeon. If given, ocular antibiotics were administered after cultures were obtained. Patients were started on topical medication post-operatively (prednisolone acetate 1\%, moxifloxacin $0.5 \%$, atropine $1 \%$ ) for at least the following week and were followed in clinic.

For statistical analysis, Snellen visual acuity was converted to logarithm of the minimum angle of resolution (logMAR) scale (Fig. 1). Nonnumeric vision was converted as follows [11]: count fingers (CF) 1.7, hand motion (HM) 2.0, light perception (LP) 2.3 , and no light perception (NLP) 3.0.

\section{Results}

Patient presentation

Two hundred and twenty-nine eyes were recorded with a diagnosis code of open globe injury. Eleven eyes were primarily enucleated or eviscerated, 39 were lost to follow-up prior to 1 month, and 11 did not have cultures obtained. Remaining 168 eyes of 166 patients were included for study, including both eyes in two cases of bilateral ocular trauma.

The average patient age at presentation was 38 years (range 1-93). Average length of follow-up was 272 days. There were 42 females (25\%). Spring (March-May) was the most common season of presentation, with 53 globes (31.5\%); winter (December-February) and summer (June-August) were next most common, with 41 and 43 globes, respectively (24.4 and 25.6\%); and fall (September-November) least common with 31 globes (18.5\%). An intraocular foreign body was found in 23 eyes (13.7\%). Biomaterial was involved in 50 globes $(29.8 \%)$. Most common mechanisms of injury were metal (26.8\%) and wood or plant material (13.1\%). Assault and fall were also common causes, each responsible for $11.3 \%$ of cases (Table 2).

\section{Antibiotic choice}

Antibiotics were administered in a majority of cases (Table 3). Intraocular antibiotics were administered in 151 eyes (90\%). Vancomycin was administered in each of these cases, usually in combination with clindamycin (79\%) but with ceftazidime in $11 \%$ and by itself in one case. Subconjunctival antibiotics were administered in $88 \%$ of cases. Tobramycin was the most common subconjunctival choice; cefazolin, vancomycin, and ceftazidime were also administered. Systemic antibiotics were administered in the emergency department or operating

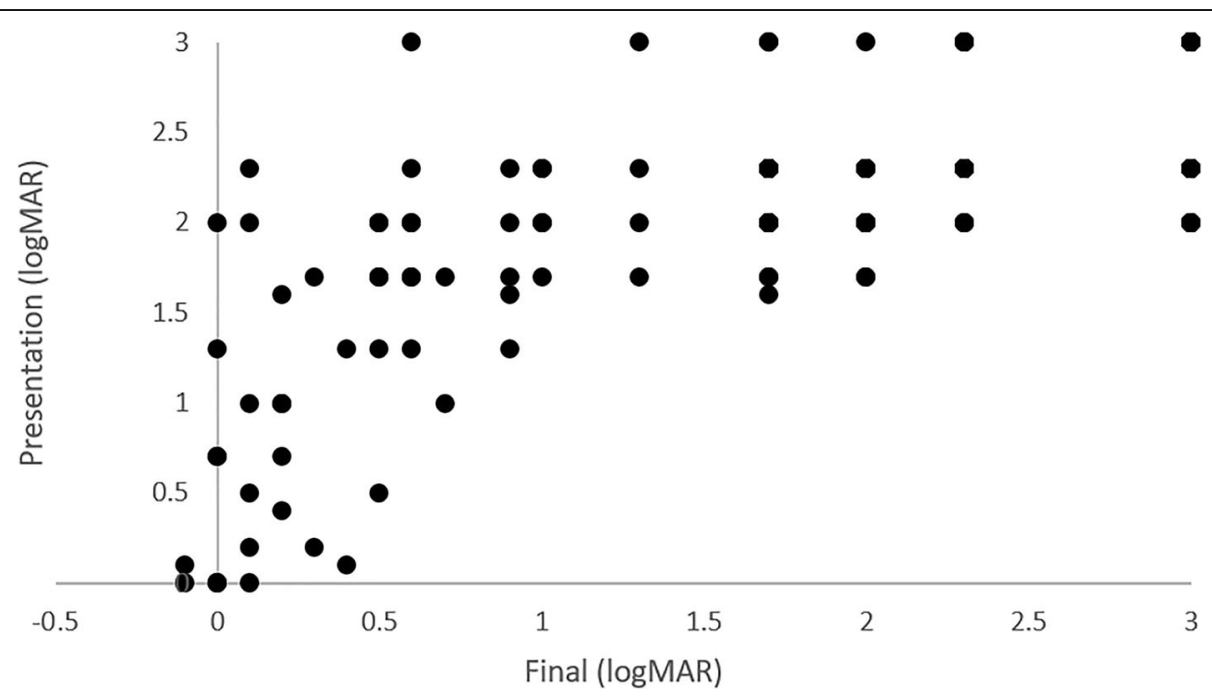

Fig. 1 Visual acuity at presentation and at final follow-up. Vision is provided in logarithm of minimum angle of resolution (logMAR) 
Table 2 Mechanism of open globe trauma

\begin{tabular}{lll}
\hline Mechanism & \# of eyes & \% of total \\
\hline Metal & 45 & 26.8 \\
Wood/plant & 22 & 13.1 \\
Assault & 19 & 11.3 \\
Fall & 19 & 11.3 \\
Bullet/BB & 17 & 10.1 \\
Glass & 10 & 6.0 \\
Motor vehicle collision & 10 & 6.0 \\
Finger & 7 & 4.2 \\
Other & 13 & 7.7 \\
Unknown & 6 & 3.6 \\
\hline
\end{tabular}

room in $79 \%$ of cases. Cefazolin was the most common (76\%); and ceftazidime, ceftriaxone, and vancomycin were less frequently administered.

\section{Culture results}

Overall, 106 (63\%) of cultures obtained were positive. Of these positive cultures, Staphylococcus species were most commonly seen (91.5\%), Streptococcus viridans was next most common (10.4\%), and $17.9 \%$ were polymicrobial. Only five samples grew fungus (Table 4). Mechanism of injury involving biomaterial was not significantly associated with culture positivity of trauma without biomaterial ( $p=0.15$ by Chi square).

\section{Development of endophthalmitis}

Two patients presented with evidence of endophthalmitis at the time of their open globe injury (1.2\%). Neither had an IOFB. In addition to wound cultures, vitreous

Table 3 Ocular and systemic antibiotics administered at time of ruptured globe repair

\begin{tabular}{lll}
\hline Antibiotic & \# of eyes & \% of total \\
\hline Intraocular & 151 & 89.9 \\
Vancomycin & 151 & 89.9 \\
+ Clindamycin & 132 & 78.6 \\
+ Ceftazidime & 18 & 10.7 \\
Subconjunctival & 147 & 87.5 \\
Tobramycin & 145 & 86.3 \\
Cefazolin & 10 & 6.0 \\
Vancomycin & 3 & 1.8 \\
Ceftazidime & 2 & 1.2 \\
Systemic & 132 & 78.6 \\
Cefazolin & 127 & 75.6 \\
Ceftriaxone & 3 & 1.8 \\
Ceftazidime & 2 & 1.2 \\
Vancomycin & 1 & 0.6 \\
\hline
\end{tabular}

Table 4 Infectious agents in open globe trauma

\begin{tabular}{llc}
\hline Organism & \# of Samples & $\begin{array}{c}\text { \% of positive } \\
\text { cultures }\end{array}$ \\
\hline Pathogenic & 97 & 91.5 \\
Staphylococcus spp. & 96 & \\
$\quad$ Coagulase-negative Staphyloccocus & 4 & \\
MSSA & 1 & 10.4 \\
$\quad$ MRSA & 11 & 5.7 \\
Streptococcus viridans & 6 & 2.8 \\
Bacillus spp. & 3 & 1.9 \\
Cladosporium & 2 & \\
Diphtheroids & 2 & \\
Micrococcus luteus & 2 & \\
Moraxella catarrhalis & 2 & \\
Enterococcus faecalis & 2 & \\
Pseudomonas spp. & 1 & \\
Klebsiella pneumoniae & 1 & \\
Morganella morganii & 1 & \\
Haemophilus influenzae & 1 & \\
Cryptococcus laurentii & 1 & \\
Enterobacter cloacae complex & 1 & \\
Acinetobacter baumannii & & \\
Non-pathogenic & & \\
Syncephalastrum racemosum & 1 & \\
Seclercia adecarboxylata & & \\
Polymicrobial & & \\
\hline
\end{tabular}

samples were obtained during their open globe repair either by pars plana vitrectomy or by vitreous tap. Both patients grew coagulase-negative staphylococcus on both their wound and intraocular cultures. None of the remaining 227 eyes screened for this study developed endophthalmitis, and their culture results were not used for the remainder of their care. In no case was topical antibiotic prophylaxis changed based on culture results.

Wound culture, in this study, had a $100 \%$ sensitivity, a $37.4 \%$ specificity, and a positive predictive value of $1.9 \%$ for endophthalmitis development, with an accuracy of $38 \%$.

\section{Culture costs}

Cost of culture media from the supplier were calculated for the standard culture analysis performed per patient (Table 1).

Per patient, total cost for supplies was $\$ 26.27$, and hospital charges for cultures were $\$ 875$. This amounts to $\$ 2206.68$ of supplies and $\$ 73,500$ of patient charges per case of endophthalmitis secondary to an open globe. 


\section{Vision outcomes}

Of the 168 eyes, 17 did not have a recordable vision secondary to patient cooperation with exam. Of those with recordable vision, mean vision was HM (logMAR 2.1) at presentation and CF (logMAR 1.8) at last follow-up. At final follow-up, vision improvement was seen in 66 eyes (43.7\% of recorded), 40 worsened (26.4\%), and 45 were stable $(29.8 \%)$ compared with presentation. The eye was eviscerated or enucleated in 21 cases (12.5\%) during the follow-up period. Final vision was correlated with vision at presentation $(r=0.75, p<0.05)$.

\section{Discussion}

Swab cultures from the globe wound were obtained preoperatively in all cases included in this study. The culture results obtained were not used clinically, and no patient without evidence of infection at presentation went on to develop endophthalmitis. For the two patients with endophthalmitis at presentation, vitreous cultures were obtained that matched wound cultures.

To the best of our knowledge, our study represents the largest study to date of wound cultures in open globe injuries. Wound cultures were positive in 63\%, compared with $23 \%$ by Rubsamen et al. [8] and $20 \%$ of conjunctival wash cultures by Bhala et al. [12] Rubsamen et al. found a low sensitivity but high specificity of wound cultures obtained intraoperatively [8]. In that study, the rate of traumatic endophthalmitis was $13 \%$ and the intraoperative cultures were clinically useful for antibiotic selection [8]. The study by Bhala et al. [12] also reported a high rate of posttraumatic endophthalmitis (40\%), and a positive culture obtained at the time of globe repair correlated to risk of infection. No distinction was made, however, between positive intra- or extra-ocular culture result in endophthalmitis risk [12]. Conjunctival and eyelid swab cultures may correlate with aqueous cultures at the time of globe repair, indicating that contamination may be from the skin flora prior to or during surgery [9].

Open globe repair has been reported to cost $\$ 850$ 3000 [13-15] in hospital charges worldwide, with higher costs for more complex cases requiring further surgery [14]. Post-operative hospitalization further increases cost, up to an average of $\$ 4500$ [14]. The societal impact can be devastating, as vision or globe loss can lead to disability and an estimated loss of $25 \%$ of earning capacity [16]. Globe loss during war, for example, is estimated to cost $\$ 3$ million over a lifetime [17].

Endophthalmitis, too, can be very costly to the healthcare system. Post-operative endophthalmitis increases Medicare charges by $\$ 3500$ [18]. Prophylactic intraocular antibiotics, however, may save the healthcare system $\$ 88,000$ over 10 years [19].
Intraocular antibiotics has been shown by metaanalysis to reduce the risk of traumatic endophthalmitis [20]. While several centers routinely use prophylactic systemic antibiotics [5, 21, 22], their use is controversial without strong supporting evidence [7]. Intravenous antibiotics were not advantageous over oral prophylaxis in a randomized controlled trial [6]; however, systemic antibiotics have not been compared with local administration in a similar fashion. Systemic antibiotics may have a poor intraocular penetration, and intravenous therapy increases hospitalization costs [23].

Patients in this study were not randomized, and the majority of patient received ocular and systemic antibiotics per surgeon preference. Although a prospective study would not utilize the insurance system for culture costs, this retrospective study collected data from an established treatment approach in place as a departmental standard. The rate of endophthalmitis seen in this study is on the lower end of the range reported in the literature [2], possibly related to the high use of prophylactic antibiotics.

\section{Conclusions}

In conclusion, cultures obtained at the time of open globe injury repair during this study period were not clinically useful or cost effective in the subsequent management of the injury. With a low rate of endophthalmitis, the positive predictive value of this test was low. We recommend obtaining cultures only if evidence of intraocular infection exists.

\section{Abbreviations}

CF: Count fingers; HM: Hand motion; IOFB: Intraocular foreign body; IRB: Institutional review board; logMAR: Logarithm of the minimum angle of resolution; LP: Light perception; NLP: No light perception

\section{Acknowledgements}

Not applicable

\section{Authors' contributions}

RTD collected and analyzed data. KAR analyzed data and was a major contributor in writing the manuscript. ALL collected and analyzed data. MGM collected and analyzed data. SSRI developed project design and was a major contributor in writing the manuscript. All authors read and approved the final manuscript.

\section{Funding}

This work was supported by an unrestricted grant from Research to Prevent Blindness, which has no involvement in study design, collection, analysis, interpretation, writing, or submission. The authors have no conflicting or proprietary interests to report. Research has not previously been published or presented.

\section{Availability of data and materials}

The datasets used and/or analyzed during the current study are available from the corresponding author on reasonable request.

\section{Ethics approval and consent to participate}

IRB approval was obtained at the University of Mississippi. Waiver of informed consent was obtained as this was a noninvasive retrospective study. 


\section{Consent for publication}

Not applicable

\section{Competing interests}

The authors declare that they have no competing interests.

\section{Author details}

'Murfreesboro Medical Clinic, 1272 Garrison Dr, Murfreesboro, TN 37129, USA. ${ }^{2}$ Department of Ophthalmology and Visual Sciences, University of Wisconsin School of Medicine and Public Health, 2880 University Avenue, Madison, WI 53705 , USA. ${ }^{3}$ Department of Ophthalmology, University of Mississippi School of Medicine, 2500 N State Street, Jackson, MS 39216, USA. ${ }^{4}$ Department of Ophthalmology, Georgetown University, Washington DC. 3800 Reservoir Road, Washington, DC 20007, USA. ${ }^{5}$ Department of Ophthalmology, University of Florida College of Medicine, 1600 SW Archer Rd, Gainesville, FL 32610, USA

Received: 21 November 2018 Accepted: 8 January 2020

Published online: 03 February 2020

\section{References}

1. Shah A, Blackhall K, Ker K, Patel D (2009) Educational interventions for the prevention of eye injuries. The Cochrane database of systematic reviews, 4(4):CD006527. ISSN 1469-493X. https://doi.org/10.1002/14651858.CD006527. pub3

2. Ahmed Y, Schimel AM, Pathengay A, Colyer MH, Flynn HW Jr (2012) Endophthalmitis following open-globe injuries. Eye (Lond) 26:212-217

3. Abouammoh MA, Al-Mousa A, Gogandi M, Al-Mezaine H, Osman E, Alsharidah AM, Al-Kharashi A, Abu El-Asrar AM (2017) Prophylactic intravitreal antibiotics reduce the risk of post-traumatic endophthalmitis after repair of open globe injuries. Acta Ophthalmol 96(3):e361-e365

4. Gokce G, Sobaci G, Ozgonul C (2015) Post-traumatic endophthalmitis: a mini-review. Semin Ophthalmol 30:470-474

5. Banker TP, McClellan AJ, Wilson BD, Juan FM, Kuriyan AE, Relhan N, Chen FV, Weichel ED, Albini TA, Berrocal AM, Sridhar J, Gregori NZ, Townsend JH, Flynn HW Jr (2017) Culture-positive endophthalmitis after open globe injuries with and without retained intraocular foreign bodies. Ophthalmic Surg Lasers Imaging Retina 48:632-637

6. Tabatabaei SA, Soleimani M, Behrooz MJ, Sheibani K (2016) Systemic Oral antibiotics as a prophylactic measure to prevent endophthalmitis in patients with open globe injuries in comparison with intravenous antibiotics. Retina 36:360-365

7. Bhagat N, Nagori S, Zarbin M (2011) Post-traumatic infectious endophthalmitis. Surv Ophthalmol 56:214-251

8. Rubsamen PE, Cousins SW, Martinez JA (1997) Impact of cultures on management decisions following surgical repair of penetrating ocular trauma. Ophthalmic Surg Lasers 28:43-49

9. $\quad$ Ariyasu RG, Kumar S, LaBree LD, Wagner DG, Smith RE (1995) Microorganisms cultured from the anterior chamber of ruptured globes at the time of repair. Am J Ophthalmol 119:181-188

10. Gupta A, Srinivasan R, Kaliaperumal S, Setia S (2007) Microbial cultures in open globe injuries in southern India. Clin Exp Ophthalmol 35:432-438

11. Lee JW, Lai JS, Yick DW, Tse RK (2010) Retrospective case series on the longterm visual and intraocular pressure outcomes of phacomorphic glaucoma. Eye (Lond) 24:1675-1680

12. Bhala S, Narang S, Sood S, Mithal C, Arya SK, Gupta V (2012) Microbial contamination in open globe injury. Nepal J Ophthalmol 4:84-89

13. Cao H, Li L, Zhang M, Li H (2013) Epidemiology of pediatric ocular trauma in the Chaoshan Region, China, 2001-2010. PLoS One 8:e60844

14. Framme C, Franz D, Mrosek S, Helbig H, Sachs HG (2008) Cost calculations for treating penetrating eye injuries within the DRG C01Z at a university eye hospital. Ophthalmologe 105:936-942

15. Pinna A, Atzeni G, Patteri P, Salvo M, Zanetti F, Carta F (2007) Epidemiology, visual outcome, and hospitalization costs of open globe injury in northern Sardinia, Italy. Ophthalmic Epidemiol 14:299-305

16. Burggraf $\mathrm{MH}$ (2016) When is the damage to the eye to be assessed as corresponding to a $25 \%$ reduction in earning ability? Klin Monatsbl Augenheilkd 233:54-56

17. Jha KN (2017) Indian soldiers need eye protection. J Clin Diagn Res 11 : NE01-NE03
18. Schmier JK, Halpern MT, Covert DW, Lau EC, Robin AL (2007) Evaluation of Medicare costs of endophthalmitis among patients after cataract surgery. Ophthalmology 114:1094-1099

19. Au CP, White AJ, Healey PR (2016) Efficacy and cost-effectiveness of intracameral vancomycin in reducing postoperative endophthalmitis incidence in Australia. Clin Exp Ophthalmol 44:803-811

20. Thevi T, Abas AL (2017) Role of intravitreal/intracameral antibiotics to prevent traumatic endophthalmitis - meta-analysis. Indian J Ophthalmol 65: 920-925

21. Li X, Zarbin MA, Langer PD, Bhagat N (2018) Posttraumatic endophthalmitis: an 18-year case series. Retina 38:60-71

22. Andreoli CM, Andreoli MT, Kloek CE, Ahuero AE, Vavvas D, Durand ML (2009) Low rate of endophthalmitis in a large series of open globe injuries. Am J Ophthalmol 147:601-608.e2

23. Du Toit N, Mustak S, Cook C (2017) Randomised controlled trial of prophylactic antibiotic treatment for the prevention of endophthalmitis after open globe injury at Groote Schuur hospital. Br J Ophthalmol 101:862867

\section{Publisher's Note}

Springer Nature remains neutral with regard to jurisdictional claims in published maps and institutional affiliations.

\section{Submit your manuscript to a SpringerOpen ${ }^{\circ}$ journal and benefit from:}

- Convenient online submission

- Rigorous peer review

- Open access: articles freely available online

High visibility within the field

- Retaining the copyright to your article

Submit your next manuscript at $\boldsymbol{\nabla}$ springeropen.com 